\title{
Microbiological Profile and Antibiogram of Bacterial Isolates Causing Urinary Tract Infection in Tertiary Care Hospital.
}

\author{
${ }^{1}$ Dr. Durgesh Dasharath Mahajan, ${ }^{2}$ Dr. Pragati Abhimanyu Bulle, \\ Assistant Professor, Dept of Medicine, Shri Vasantrao Naik Government Medical College, Yavatmal. \\ Assistant Professor, Dept of Microbiology, Shri Vasantrao Naik Government Medical College, Yavatmal.
}

\begin{abstract}
:
Urinary tract infections (UTIs) are counted among the most common infections in humans. In spite of the availability and use of the antimicrobial drugs, UTIs caused by bacteria have been showing increasing trends. Patients diagnosed clinically as UTI during the study period (January 2015 to December 2015) in a Shri Vasantrao Naik Government Medical College and Hospital, Yavatmal (Maharashtra) were included in the study. Urine sample of these patients were tested for Culture and antibiotic susceptibility testing. A total of 472 urine samples were included in the study of that 368 from female patients and 104 from male patients. Out of 472 urine samples urine culture was positive in $200(42.37 \%)$ whereas in 272 urine culture was negative. Most common etiological organisms of UTI isolated were Escherichia coli 64(32\%) followed by Klebsiella species 61(30.5\%), Staphylococcus aureus 26(13\%), Coagulase negative staphylococci (CoNS) 11(5.5), Pseudomonas aeruginosa 11(5.5\%) Proteus species 7(3.5\%), Citrobacter species 4(2\%), Enterococci species 4(2\%), Acinetobacter species 2(1\%), Streptococcus pyogenes $1(0.5 \%)$. Most effective antibiotics were imipenem, nitrofurantoin, amikacin and piperacillin-tazobactum. For prevention of UTIs, implementation of strict infection control guidelines, effective hand washing and judicious use of antimicrobials is mandatory to prevent the emergence of drug resistance among uropathogens.
\end{abstract}

Keywords: Urinary tract infection, Antibiotic sensitivity, Gram Negative, Gram Positive.

\section{Introduction}

Urinary Tract Infections (UTIs) are defined by the presence of a growth of more than $10^{5}$ colony forming units (CFU) of bacteria per $\mathrm{ml}$ of urine for asymptomatic individual and much lower for symptomatic individual $\left(\sim 10^{3} \mathrm{CFU} / \mathrm{ml}\right) .{ }^{1}$ In urine sample obtained by supra pubic aspiration or in-and-out catheterization and in samples from a patient with an indwelling catheter, colony count of $10^{2}-10^{4} / \mathrm{ml}$ generally indicates infection. ${ }^{2}$

Urinary tract infection (UTI) is one of the most commonly occurring community acquired infections in developing countries owing to lack of sanitation and unhygienic toilet habits. ${ }^{3}$ Urinary tract infections (UTI) are caused by pathogenic invasion of the urinary tract which leads to an inflammatory response of the uroepithelium. Proliferation of bacteria in the urinary tract is the cause of urinary tract infection. ${ }^{4}$

An estimate of patients suffering from UTI is around 150 million per annum across the globe which may rise to $75 \%$ in the female population by the age of 24 years and $15-25 \%$ of this group may suffer from the relapse of this diseases. ${ }^{5}$ UTI in men are less common. It has been observed that up to one-third of all women will experience UTI at some point during their lifetime. This finding has been attributed to three features that facilitate ascending infections into bladder, namely a short urethra, the proximity of urethra to anus and colonization of vagina by the fecal flora. ${ }^{6}$ About 150 million people are diagnosed with UTI each year, costing the global economy in excess of 6 billion dollars. ${ }^{7}$

\section{Aims and objective}

The present study was undertaken with the following aims and objectives.

1) To study the etiological profile of UTI

2) To determine the antibiotic sensitivity pattern of the bacterial isolates.

This was a retrospective study conducted for a period of one year (January 2015 to December 2015) in a Shri Vasantrao Naik Government Medical College and Hospital, Yavatmal (Maharashtra).

Inclusion criteria $-\mathrm{i})$ With fever $\left(>38^{\circ} \mathrm{C}\right)$ and chills ii) Patient showing one or more of the following symptoms Burning micturition, increased frequency, urgency of urine, dysuria and pain lower abdomen / flank pain/ supra pubic pain.

Exclusion criteria - i) Asymptomatic patients. ii) Patients already on antibiotic treatment (duration of 5-7 days) iii) Age less than 12 years. iv)Patients on indwelling catheters. Informed consent was taken from all the subjects participated in the study after explaining the study protocol. About $30 \mathrm{ml}$ of clean catch midstream urine sample were collected in $100 \mathrm{ml}$ sterile, dry, leak-proof container with instructions on how to collect a clean catch 
midstream urine (MSU). Urine is an excellent culture media and bacteria will multiply if specimen is left at room temperature for any appreciable time. For this reason, urine specimen was transported to the laboratory immediately after obtaining and was processed within one hour or in case of delay they were refrigerated at $4^{\circ} \mathrm{C}$ (upto 24 hours), until culture can be performed. ${ }^{8}$

\section{Direct microscopy}

Wet mount examination was performed to look for the presence of pus cells, epithelial cells, red blood cells, crystals or microorganisms. Sample culture, Bacterial identification and Antibiotic susceptibility testing Urine specimen was inoculated on Blood agar and MacConkey agar and incubated in incubator at $37{ }^{0} \mathrm{C}$. Various organisms were identified on the basis of colony morphology and standard biochemical tests. ${ }^{9}$ The isolates were subjected to antimicrobial susceptibility testing by Kirby Bauer disk diffusion method as per CLSI guidelines 2014. ${ }^{10,11}$

The following antibiotics used were: Nitrofurantoin $(300 \mu \mathrm{g})$, Amikacin $(30 \mu \mathrm{g})$, Cotrimoxazole $(25 \mu \mathrm{g})$, Gentamycin $(10 \mu \mathrm{g})$, Ciprofloxacin $(5 \mu \mathrm{g})$, Ceftazidime $(30 \mu \mathrm{g})$, Norfloxacin $(10 \mu \mathrm{g})$, Ampicillin $(10 \mu \mathrm{g})$ and Imipenem $(10 \mu \mathrm{g})$, Piperacillin-tazobactum $(100 / 10 \mu \mathrm{g})$.

\section{Observations and results :}

A total of 472 urine samples were included in the study of that 368 from female patients and 104 from male patients. Out of 472 urine samples urine culture was positive in 200(42.37\%) whereas in 272 urine culture was negative. (Table 1)

Table 1 : Frequency of culture positives in males and females.

\begin{tabular}{|c|c|c|c|c|c|c|c|}
\hline \multirow{2}{*}{$\begin{array}{l}\text { Total no. of } \\
\text { samples }\end{array}$} & \multirow{2}{*}{$\begin{array}{l}\text { Total no. of } \\
\text { culture positives }\end{array}$} & \multicolumn{3}{|c|}{ Female } & \multicolumn{3}{|c|}{ Male } \\
\hline & & Number & Positive & $\%$ & Number & Positive & $\%$ \\
\hline 472 & 200 & 368 & 165 & 44.83 & 104 & 35 & 33.65 \\
\hline
\end{tabular}

Table 2 : Age wise distribution of samples and their positivity.

\begin{tabular}{|l|l|l|l|l|l|l|}
\hline \multirow{2}{*}{$\begin{array}{l}\text { Age in } \\
\text { years }\end{array}$} & Total no. of samples & \multicolumn{2}{l|}{ Female } & \multicolumn{2}{l|}{ Male } & $\begin{array}{l}\text { Total no. of culture } \\
\text { positives }\end{array}$ \\
\cline { 3 - 7 } & & Number & Positive & Number & Positive & \\
\hline $12-20$ & $55(11.65 \%)$ & 51 & 18 & 4 & 2 & $20(10 \%)$ \\
\hline $21-40$ & $239(50.64 \%)$ & 180 & 96 & 59 & 22 & $118(59 \%)$ \\
\hline $41-60$ & $125(26.48 \%)$ & 92 & 36 & 33 & 9 & $45(22.5 \%)$ \\
\hline $61-80$ & $49(10.38 \%)$ & 42 & 15 & 7 & 2 & $17(8.5 \%)$ \\
\hline$>80$ & $4(0.85 \%)$ & 3 & 0 & 1 & 0 & $0(0 \%)$ \\
\hline Total & $472(100 \%)$ & 368 & 165 & 104 & 35 & $200(100 \%)$ \\
\hline
\end{tabular}

Maximum number of samples (50.64\%) were from the age group 21-40 years and maximum positivity (59\%) was from the same age group. (Table 2)

Table 3: Microbial profile of UTI

\begin{tabular}{|l|l|l|}
\hline Oraganisms & Number & Percentage (\%) \\
\hline Gram negative bacilli & $\mathbf{1 4 9}$ & $\mathbf{7 4 . 5}$ \\
\hline Escherichia coli & 64 & 32 \\
\hline Klebsiella species & 61 & 30.5 \\
\hline Proteus species & 07 & 3.5 \\
\hline Citrobacter species & 4 & 2 \\
\hline Acinetobacter species & 2 & 1 \\
\hline Pseudomonas aeruginosa & 11 & 5.5 \\
\hline Gram positive bacteria & $\mathbf{4 2}$ & $\mathbf{2 1}$ \\
\hline Staphylococcus aureus & 26 & 13 \\
\hline Coagulase negative staphylococci (CoNS) & 11 & 5.5 \\
\hline Streptococcus pyogenes & 1 & 0.5 \\
\hline Enterococci species & 4 & 2 \\
\hline Fungus & $\mathbf{9}$ & $\mathbf{4 . 5}$ \\
\hline Candida albicans & 9 & 4.5 \\
\hline Total & 200 & \\
\hline
\end{tabular}

Table 3 shows that, the isolates included both gram positive and gram negative organisms. Of the 200 isolates, gram negative bacteria accounts for $149(74.5 \%)$ while gram positive bacteria accounts for $42(21 \%)$. 
Table 4 : Antibiotic Susceptibility pattern of bacterial isolates from urine samples of patients

\begin{tabular}{|l|l|l|l|l|l|l|l|l|l|l|}
\hline \multirow{2}{*}{ Bacteria } & \multicolumn{9}{|c|}{ Antibiotics } \\
\cline { 2 - 12 } & A & Ak & Caz & Ci & Cot & Gen & Nor & Ni & PIT & I \\
\hline Escherichi coli $(\mathrm{n}=64)$ & 10 & 52 & 45 & 31 & 30 & 45 & 39 & 48 & 41 & 50 \\
\hline Klebsiella spp $(\mathrm{n}=61)$ & 11 & 50 & 37 & 31 & 28 & 40 & 37 & 49 & 40 & 49 \\
\hline Proteus $\operatorname{spp}(\mathrm{n}=7)$ & 2 & 6 & 5 & 4 & 2 & 4 & -- & 5 & 5 & 6 \\
\hline Citrobacter spp $(\mathrm{n}=4)$ & 1 & 4 & 2 & 2 & 2 & 3 & 3 & 3 & 3 & 3 \\
\hline Acinetobacte $\operatorname{spp}(\mathrm{n}=2)$ & 0 & 2 & -- & -- & 1 & 1 & 2 & 2 & 2 & 2 \\
\hline Ps.aeruginosa $(\mathrm{n}=11)$ & 3 & 9 & 7 & 4 & 3 & 5 & 9 & 9 & 9 & 10 \\
\hline Staph.aureus $(\mathrm{n}=26)$ & 5 & 21 & -- & 18 & 11 & 15 & 20 & 10 & -- & -- \\
\hline CoNS $(\mathrm{n}=11)$ & 3 & 8 & -- & 7 & 5 & 4 & 6 & 9 & -- & -- \\
\hline Strept. Pyogenes $(\mathrm{n}=1)$ & 1 & -- & -- & 1 & 1 & -- & 1 & 1 & -- & -- \\
\hline Enterococci $(\mathrm{n}=4)$ & 2 & 3 & -- & -- & -- & 2 & 4 & 4 & -- & -- \\
\hline
\end{tabular}

A - Ampicillin, Amc - Amoxyclav, Ak- Amikacin, Caz- Ceftazidime, Ci- Ciprofloxacin, Cot- Co-trimoxazole, G- Gentamicin, NiNitrofurantoin, Nor- Norfloxacin, PIT- Piperacillin+Tazobactem , I- Imipenem, Streptococcus

The most effective antibiotic in case of gram negative bacteria was Amikacin followed by Nitrofurantoin, Piperacillin+Tazobactem and Gentamicin while in case of gram positive bacteria most effective antibiotic was Amikacin followed by Norfloxacin and ciprofloxacin. (Table 4) Antifungal susceptibility testing of Candida spp. isolates was not done.

\section{Discussion}

UTI accounts for huge burden on health care systems due to high prevalence of infection in both community and nosocomial settings. UTI is caused by variety of pathogens including E. coli, Klebsiella spp, Proteus spp, Staphylococcus aureus, Coagulase negative staphylococci including Staphylococcus saprophyticus and Staphylococcus epidermidis and also Candida spp. Continuous surveillance of antibiotic susceptibility patterns of uropathogens at local level is crucial in dealing with emerging problems of antibiotic resistance and provides assistance in managing effective initial therapy. ${ }^{1}$

In present study urine culture positivity was $42.37 \%$ which is very similar to study done by Anup Shah et al 2015(43.07\%) ${ }^{12}$, Shaista Banoet al $2014(41.18 \%)^{1}$ and Telkar et al $2015(40 \%) .{ }^{14}$ Some studies reported higher positivity like V. Vijaya Swetha et al 2014 (61.91\%), Razak S.K et al (2012) (71.72\%) and Das RN et al (2006) $(71.6 \%){ }^{14,15,16}$

The age and sex wise analysis showed a higher incidence of urinary tract infection in 21-40 years age group in females which can be explained by the fact that urinary tract infections are more common in the reproductive age group. This is because in females the urethra has close proximity and the colonic bacteria have an easy access to it. Females are more prone to UTI than males as they lack bacteriostatic property of prostatic secretions. ${ }^{17,18}$

In our study also most of the samples (50.64\%) were from the age group 21-40 years and maximum positivity $(59 \%)$ was from the same age group. This correlates with other studies by Bashir MF et al $(2008)^{19}$ and Getenet B. et al (2011). ${ }^{20}$ In a studies conducted by Beyene G et al (2011) and V. Vijaya Swetha et al 2014 reported $53.5 \%$ and $48.34 \%$ were in the age group between $21-40$ years respectively. ${ }^{21,14}$

Like the study by Lekha Tuli et al, the maximum patients presented with the complaint of burning micturition, fever, and abdominal discomfort. ${ }^{22}$

In present study gram negative bacilli 149 (74.5\%) were the predominant bacterial isolates followed by Gram positive cocci $42(21 \%)$ which is consistent with another studies. ${ }^{23,24,25}$ Overall the most common bacterial isolates were Escherichia coli 64(32\%) followed by Klebsiella species 61(30.5\%), Staphylococcus aureus 26(13\%), Coagulase negative staphylococci (CoNS) 11(5.5), Pseudomonas aeruginosa 11(5.5\%) Proteus species 7(3.5\%), Citrobacter species 4(2\%), Enterococci species 4(2\%), Acinetobacter species $2(1 \%)$, Streptococcus pyogenes $1(0.5 \%)$.

Like our study Klebsiella spp was reported as the second most frequently implicated organism after E.coli in UTI in some other studies. ${ }^{26,27}$ Also E.coli $(41.73 \%)$ was the most common isolated organism in study conducted by Shwetha et al. ${ }^{14}$ This was in correlation with other studies by Gupta K.D et al (1999), Moges et al (2002) and Sibi et al (2011). ${ }^{28,29,4}$ And the second most common isolated pathogen was Klebsiella spp in study conducted by Shwetha et al accounting for $22.90 \%$. This correlates with the studies of Khameneh et al (2009) and Chin et al (2011)..$^{14,30,31}$

But Ehinmidu (Ehinmidu, 2003) and Aboderin et al. (2009) recorded P. aeruginosa and Klebsiella spp, respectively as the predominant bacteria. ${ }^{26,32} P$. aeruginosa was also reported as the second most common bacterial isolate in UTI from studies in India by Tambekar et al. (2006) ${ }^{33}$ and Lafia, Nigeria by Kolawole et al. (2009). ${ }^{34}$

In our study we found $4.5 \%$ isolates were Candida spp while Venktesh et al noted $6 \%$ isolates were Cadida spp. $^{35}$ 
In this study, among gram negative bacilli isolated from UTI, E.coli was sensitive to imipenem, nitrofurantoin, amikacin and piperacillin-tazobactum. A high level of bacterial resistance was seen to ampicillin , ciprofloxacin and ceftazidime. Studies conducted by Mangaiarkkarasi et al. (2013) and Shalini et al. (2011) showed similar antibiotic pattern. ${ }^{36,37}$ Amikacin, imipenem, piperacillin-tazobactum, norfloxacin, and nitrofurantoin were more effective against Pseudomonas spp. and Acinetobacter spp. isolated in present study. Nitrofurantoin is a urinary antiseptic. In their study Joshi et al. (2011) discussed very positive outcomes with Nitrofurantoin as it is cost effective and easily available in developing countries. Besides it can be used safely in pregnancy $^{38}$ and causes narrow tissue distribution. ${ }^{39}$ In their study, Shaifali et al. (2012) from Lucknow also found the isolates exhibiting maximum susceptibility to Nitrofurantoin. ${ }^{40}$

The high prevalence of resistance to the community used antibiotics such as ampicillin, ciprofloxacin and tetracycline was also noted in some studies. ${ }^{41,42,43}$

Niranjan et al. (2014) reported multiple drug resistance in uropathogenic E.coli, which could be due to its widespread prevalence in the community. ${ }^{44}$ Lack of guidelines for appropriate use of Antimicrobial agents is another factor responsible for spread of resistance. ${ }^{45}$

In this study, the frequency of ESBL producing organisms among gram negative bacterial isolates was found to be $30 \%$. A similar frequency of ESBL producing organismswas observed by Telkar et al (29.03\%), Dugal et al $2013(27.67 \%)$ and Garg et al (25\%). ${ }^{13,46,24}$ Detection of ESBL isolates is essential as these ESBL producing gram negative bacilli appear susceptible in-vitro to certain $\beta$ Lactam antimicrobial agents, yet results in treatment failures. So, proper identification is necessary. ${ }^{13}$

In our study gram positive cocci were sensitive to amikacin followed by norfloxacin, nitrofurantoin and ciprofloxacin.

The prevalence of MRSA in urinary isolates in our study was $28 \%$. While other studies from India found $31.1 \%$ (Rajaduraipandhi et al ), 54.85\% (Anupurba et al) and $66.6 \%$ (Garg et al) MRSA strains in urine samples. ${ }^{47,48,24}$

The present study gives an idea about the common trend of increasing antibiotic resistance of uropathogens in this region which could be due to indiscriminate or under dose of antibiotic use. Thus this data may help the physician in proper treatment of urinary tract infections and avoid use of resistant antibiotics.

\section{Conclusion}

The pattern of antimicrobial resistance of bacteria producing UTI varies in different regions. Monitoring of antimicrobial susceptibility can aid clinicians for prescribing appropriate antibiotics and in prevention of development of drug resistance.

\section{References}

[1]. ShaistaBano, Sarfraz A Tunio, AmeerAfzalMenom, Hakim Detho,RozinaBano, KalpanakumariEvaluation of antibiotic susceptibility patterns of uropathogens circulating in Hydrabad, Pakisthan. Khyber Med Univ J 2014;6(3):110-115.

[2]. Rama Biswas, RaihanRabbani, HasanShahrear Ahmed, Mohammed AbdusSatterSarkar, NahidaZafrin, Md. MotlaburRahman. Antibiotic sensitivity pattern of urinary tract infection at a tertiary care hospital. Bangladesh Crit Care J 2014 March;2(1):21-24

[3]. Humayun, T., Iqbal, A. 2012. The Culture and Sensitivity Pattern of Urinary Tract Infections in Females of Reproductive Age Group. Ann. Pak. Inst. Med. Sci., 8(1): 19-22.

[4]. Sibi, G., Devi, A. P., Fouzia, K., and Patil, B. R. 2011. Prevalence, microbiologic profile of urinary tract infection and its treatment with trimethoprim in diabetic patients. Research Journal of Microbioogy. 6: 543-551.

[5]. Varsha Rani Gajamer, Hare KrishnaTiwari, PremDorjeeBhutia, SankhaSubraSen, RanadeepGhosh, ArunabhaSarkar. Detection of antibiotic resistance pattern with ESBL producers and MRSA among uropathogens at tertiary health care centre, North Bengal. International Journal of Pure and Applied Bioscience 2015 April;3(2):522-533.

[6]. ZinnatShahina, Md. Jahedul Islam, JesminAbedin, A.H.M. IshaqueChowdhary, Md. Arifuzzaman. A study of antibiotic susceptibility and resistance pattern of E. coli causing urinary tract infection in Chittagong, Bangladesh. Asian Journal of Biological Sciences 2011;4(7):548-555.

[7]. Hari P Kattel, Shyam K. Mishra, Jyoti Acharya, Basisata P. Rijal, et al. 2012. Antibiotic sensitivity profile of different uropathogens in a tertiary care center in Nepal. Journal of Nepal Association of Medical Laboratory Science, 11(1): 19-33

[8]. Gradwohl's clinical laboratory methods and diagnosis. Volume 2, Part VII, page 1136-1139.

[9]. Collee JG, Fraser AG, Marmion BP, Simmons A (eds). Mackie and McCartney Practical Medical Microbiology. 14 ${ }^{\text {th }}$ ed. Edinburgh: Churchill Livingstone; 1996.

[10]. Bauer AW, Kirby WMM, Sherris JC, Turck M. Antibiotic susceptibility testing by a standardized single disk method. Am J Clin Pathol 1966;45:493-96.

[11]. CLSI. Performance Standards for Antimicrobial Susceptibility Testing; Twenty-First Informational Supplement. CLSI document M100-S21. Wayne, PA: Clinical and Laboratory Standards Institute; 2014

[12]. Anup Saha, Tapan Majumdar, Arunabha Dasgupta, Purnima Saumandal. Prevalence of extended spectrum beta-lactamase [ESBLs] among uropathogens at a tertiary care hospital in Tripura. The Health Agenda 2015 April;3(2):555-62.

[13]. Telkar A, Barakha, Baragundi M. Bacteriological Profile, Antibiotic Sensitivity Pattern and Detection of ESBL Production in the Isolates of UTI in Tertiary Care Hospital, Davangere, India. International Journal of Science and Research. Volume 4 Issue 7 , July 2015 .

[14]. V.Vijaya Swetha, U.Sreenivasa Rao, P. Hema Prakash, S. Subbarayudu. Aerobic bacteriological profile of urinary tract infections in a tertiary care hospital. Int.J.Curr.Microbiol.App.Sci (2014) 3(3): 120-125

[15]. Razak, S. K., and Gurushantappa, V. 2012. Bacteriology of urinary tract infection and antibiotic susceptibility pattern in a tertiary care hospital in South India. Int J Med Sci Public Health. 1:109112. 
[16]. Das, R. N., Chandrashekhar, T. S., Joshi, H. S., Gurung, M., Shrestha, N., and Shivananda, P. G. 2006. Frequency and susceptibility profile of pathogens causing urinary tract infections at a tertiary care hospital in western Nepal. Singapore Med J. 47(4): 281.

[17]. Al-Jebouri, M.M. 1989. The Effect of Sublethal Concentrations of Disinfectants on Antibiotic-Resistant Staphylococcus aureus. J. Hospital Infec, 14(4):14-19.

[18]. Dielubanza, E. J., and Schaeffer, A. J. 2011. Urinary tract infections in women. The Medical clinics of North America. 95(1): 2741

[19]. Bashir, M. F., Qazi, J. I., and AhmadN Riaz, S. 2008. Diversity of urinary tract pathogens and drug resistant isolates of Escherichia coli in different age and gender groups of Pakistanis. Tropical Journal of Pharmaceutical Research September. 7(3): 1025-1031.

[20]. Getenet, B., and Wondewosen, T. 2011. Bacterial Uropathogens in Urinary tract infections and Antibiotic susceptibility pattern in JIMMA University specialized hospital, Southwest Ethiopia. Ethiop J Health Sci. 21(2): 141-146

[21]. Beyene, G., Tsegaye, W. 2011. Bacterial uropathogens in urinary tract infection and antibiotic susceptibility pattern in jimma university specialized hospital, southwest Ethiopia. Ethiop. J. Health Sci., 21: 1416.

[22]. Lekha Tuli, Sujeet Rai, Dilshad Arif, Deepak K. Singh. 2016. Bacteriological profile and Antimicrobial Susceptibility pattern of isolates from Urinary Tract Infections in Eastern Uttar Pradesh, India. Int.J.Curr.Microbiol.App.Sci. 5(3): 428-435.

[23]. Al-Jebouri, O.A.H. 2006. The relationship between urinary caliculi types and urinary tract infections among patients in Tikrit District. M. Sc. Thesis, College of Medicine, Tikrit University, Tikrit.

[24]. Garg N, Shukla I, Rizvi M, Ahmed SA, Khatoon A, Khan F. Microbiological Profile and Antibiotic Sensitivity Pattern of Bacterial Isolates Causing Urinary Tract Infection in Intensive Care Unit Patients in a Tertiary Care Hospital in Aligarh Region, India. Int.J.Curr.Microbiol.App.Sci (2015) Special Issue-1: 163-172

[25]. Rangari A A, Sharma S, Tyagi N, Singh P, Singh G, Thakur R. Antibiotic Susceptibility Pattern of Bacterial Uropathogens Isolated from Patients at a Tertiary Care Hospital in Western Uttar Pradesh of India. Int.J.Curr.Microbiol.App.Sci (2015) 4(10): 646-657

[26]. Aboderin OA, Abdu A, Odetoyinbo BW, Lamikanra A. 2009. Antimicrobial resistance in Esherichia coli strains from urinary tract infections. Journal of National Medical Association, 101: 1268-73.

[27]. Abubakar EM. 2009. Antimicrobial susceptibility pattern of pathogenic bacteria causing urinary tract infections at the Specialist Hospital, Yola, Adamawa State, Nigeria. Journal of Clinical Medicine Research, 1(1): 001-008.

[28]. Gupta, K. D., Scholes, W. E., and Stamm. 1999. Increasing prevalence of antimicrobial resistance among uropathogens causing acute uncomplicated cystitis in women. Journal of the American Medical Association. 281: 736-738.

[29]. Moges, A. F., Genetu, A., and Mengistu, G. 2002. Antibiotic sensitivities of common bacterial pathogens in urinary tract infections at Gondar Hospital, Ethiopia. East Afr. Med. J. 79: 140142.

[30]. Chin, B. S., Kim, M. S., and Han, S. H. 2011. Risk factors of all-cause inhospital mortality among Korean elderly bacteremic urinary tract infection patients. Archives of Gerontology and Geriatrics. 52: 5055.

[31]. Khameneh, Z. R., and Afshar, A. T. 2009. Antimicrobial susceptibility pattern of urinary tract pathogens. Saudi J Kidney Dis Transpl. 20: 251-253.

[32]. Ehinmidu JO. 2003. Antibiotic susceptibility patterns of urine bacterial isolates in Zaria, Nigeria. Tropical Journal of Pharmaceutical Research, 2(2): 22328.

[33]. Tambekar DH, Dhanorkar DV, Gulhane SR, Khandelwal VK, Dudhane MN. 2006. Antibacterial susceptibility of some urinary tract pathogens to commonly used antibiotics. African Journal of Biotechnology, 5(17): 1562-65

[34]. Kolawole AS, Kolawole OM, KandakiOlukemi YT, Babatunde SK, Durowade KA, Kolawole CF. 2009. Prevalence of urinary tract infection among patients attending Dalhatu Araf Specialist Hospital, Lafia, Nassarawa State, International Journal of Medicine and Medical Sciences, 1(5): 163-7.

[35]. Venkatesh RK, Prabhu MM, Nandakumar K, Sreedhara K, Pai R. Urinary Tract Infection Treatment Pattern of Elderly Patients in a Tertiary Hospital Setup in South India: A Prospective Study. J Young Pharm, 2016; 8(2): 108-113

[36]. Mangaiarkkarasi, A., Meher Ali, R., Gopal. 2013. Study of Antimicrobial Susceptibility Pattern of Escherichia coli Isolated from clinical specimens in a Teaching Hospital, Pondicherry. RJPBCS, (4): 1365

[37]. Shalini, Joshi, M.C., Rashid, M.K., Joshi, H.S. 2011. Study of Antibiotic Sensitivity Pattern in Urinary Tract Infection at a Tertiary Hospital. NJIRM., 2(3).

[38]. Delzell, J.E.Jr., Leferre, M.L. 2000. Urinary tract infections during pregnancy. Am. Fam. Physician, 61(3): 713-721.

[39]. James, A.K., Laurie, J., Clyde, T., et al. 2002. Trends in Antimicrobial Resistance among Urinary Tract Infection Isolates of Escherichiacoli from Female Outpatients in the United States. Antimicrob. Agents Chemother., 46(8): 2540-2545.

[40]. Shaifali, I., Gupta, U., Mahmood, S.E., Ahmad, J. 2012. Antibiotic susceptibility patterns of urinary pathogens in female outpatients. North. Am. J. Med. Sci., 163-9.

[41]. Janet O. Olaitan, Ph.D. 2006. Asymptomatic bacteriuria in female students population of a Nigerian university. Internet $\mathbf{J}$ Microbiology, 2: 2-6.

[42]. Nurullaev RB. 2004. The role of Asymptomatic bacteriuria in epidemiologic study of the urinary tract infection (UTI). Lik Aprava, 7: 23-25.

[43]. Orrett FA, Davis GK. 2006. A comparison of antimicrobial susceptibility profile of urinary pathogens for the years, 1999 and 2003. West Indian Medical Journal, 55(2): 95-99.

[44]. Niranjan, V., Malini, A. 2013. Antimicrobial resistance pattern in Escherichia coli causing urinary tract infection among inpatients. Ind. J. Med. Res., 139: 945-948.

[45]. Mahmoud, Aly., Hanan, H., Balkhy. 2012. The prevalence of antimicrobial resistance in clinical isolates from Gulf Corporation Council countries. Antimicro. Resis. Infect. Con., (1): 26.

[46]. S. Dugal, H. Purohit. Antimicrobial susceptibility profile and detection of extended spectrum betalactamase production by gram negative uropathogens. International journal of Pharmacy and Pharmaceutical Sciences 2013;5(4):434-438

[47]. Rajaduraipandi, K., Mani, K.R., Panneerselvam, K., Mani, M., Bhaskar, M., Manikandan, P. 2006. Prevalence and antimicrobial susceptibility patterns of methicillin resistant Staphylococcus aureus: A multicentre study. Indian J. Med. Microbiol., 24(1): 34 -38.

[48]. Anupurba, S., Sen, M.R., Nath, G., Sharma, B.M., Gulati, A.K., Mohapatra, T.M. 2003. Prevalence of methicillin resistant Staphylococcus aureus in a tertiary referral hospital in eastern Uttar Pradesh. Indian J. Med. Microbiol., 21(1): 4951. 